\title{
EDITORIAL
}

\section{THE HUMAN TISSUE ACT AND ITS RELEVANCE TO FORENSIC PRACTICE IN SRI LANKA}

\author{
Induwara Gooneratne \\ Department of Forensic Medicine, Faculty of Medicine, University of Peradeniya, Sri Lanka
}

Forensic practitioners essentially deal with the dead and assist legal fraternity in unravelling purported mysteries surrounding deaths. In doing so, they perform autopsies, collect and store human tissues for analysis, manipulate human tissues for scientific scrutiny and later dispose of these collected tissues. The authority for post-mortem examination and allied pertinent investigations is vested on the practitioner through either a court order or the Inquirer's order .The authority in issuing such an order by the inquirer or court in Sri Lanka is derived through the criminal procedure code Act. However, the legal framework does not specify logistics or manner in which the forensic practitioners should collect, store or analyse samples and then dispose of them. In routine practice it is customary that the consent from the next of kin of the deceased is also taken for post mortem examination and for collection of tissues even in the presence of a court or inquirer's order.

In this line of discussion, a few important issues stem up. On what authority forensic practitioners retain specimens - for example bones or histological slides prepared after having arrived at a medical cause of death? Should they be discarded when the cause of death is arrived at or at least when the court case is over, if there is one? Is there a necessity for retention of specimens of cases now, when there are facilities for digital photographs? All practitioners including myself at times tend to retain specimens with the justification that we will either use them for teaching purposes, research purposes or to perhaps substantiate our opinions further in court, perhaps assuming that the court or jury may want to see the specimens later!. However, the original order of court was for and the consent from the relatives were taken merely to arrive at a cause of death which assist in deciding on the manner of death. Then, is the action of keeping these specimens for teaching purposes without a further court order and an extended consent from relatives is ultra vires, unethical or is amounting to a punishable offense? In the absence of a specific legal framework addressing such issues which are part and parcel of forensic practice, this paper attempts to explore the Transplantation of Human Tissue act in Sri Lanka (no 48 of 1987) and see if it has helpful answers to the above mentioned research questions.

As the act itself introduces, the primary object of this particular enactment is to cover organ donation for transplant purposes within the territory of Sri Lanka. Despite this being the main purpose of the act, it is evident that this law also deals with organ donations for research and teaching purpose. The act clearly indicates a person above the age of twenty one is eligible to make a decision in regard to donating his entire body or its parts for medical or dental research, therapeutic/transplant purposes or for the use of medical or dental education. The article 2 of the act stipulates that;

'Any person above the age of twenty-
one years, may consent to the
donation, to take effect upon his
death, of his body or any part thereof
or any to be used for the advancement
of medical and dental education, for
the purposes of research, for the
advancement of medical science or
therapy or for use on any living
person'

This means that any competent adult individual is entitled to decide if he wishes to donate his entire body or body parts to the above specified purposes before his death. The law is very clear about how such approval or consent be given by any adult who is above twenty one years. It is desirable that the prospective donor gives his consent voluntarily after having understood as to what may happen to his body or his body parts after they are being donated. 
The tendering of consent by the adult should preferably be in writing which should be attested by two competent witnesses. What is meant by being competent is that these individuals are required to be rational adults with a sound mind above twenty one years and that they witness that the consent was provided before them voluntarily with no pressure or force what so ever at the donor. The concern I raise here is that at most times, the consent is obtained by the donor but regrettably fail to get two witnesses to validate the consent. In the absence of such two witnesses before them, validating his consent can make it invalid. Further, it is always desirable to allow two witnesses the donor knows personally rather than those known to the practitioner or the institute to avoid any conflict of interest. Both the witnesses and the donor must be present at the same time witnessing the donor's signature after having carefully reviewed the meaning and extent to which the consent is provided. Of course, the donor can revoke his consent at anytime.

In the absence of a prior consent by the deceased, the act further allows the next of kin or immediate relatives to give consent for donation of entire body or parts for medical or dental research, therapy/transplant or medical or dental education. In this regard too, the consent by the relatives should be voluntary without undue influence and that their written consent should have been witnessed by two competent witnesses being present at the time of giving consent. It is pertinent that the donor or the relatives of the donor who provides consent understands what happens to the body after it is being donated: whether it is being taken for education, therapy or research and the nature and extent or such research therapy and education. It is important that the relative who provides consent is aware that the deceased has had no prior directive against such donations or that there was no revoke of a previous consent given by the donor for such donation. In the event of a child both the parents or in the absence of parents the legal guardian/s may approve donating body parts of the deceased child where applicable.

According to the legal framework of Sri Lanka, the donees can only include a medical practitioner, a dental practitioner, a government hospital or institution prescribed in the consent form. It is desirable that the donor is aware where his body parts are donated to and to what purpose. In the event a person dies and the relatives are aware that there was such a directive as to donate his body or body parts to a specified purposes, the relatives then may authorise removal of such body or body part. However, if the relatives believes that such a directive has been revoked by the deceased or that the relatives has other compelling evidence to believe any unethical or criminal activity then the relatives may object to such removal.

The act seems to provide provisions to remove unclaimed bodies in hospitals or other respective institutions. Accordingly when a body has not been claimed after seven days of declaration of death, the prescribed officer of such institution can authorise such unclaimed bodies for any post mortem examination or for anatomical research.

The body or body parts should not be used for any other purpose other than what the donor has agreed specifically. The act, under section thirteen specifically prohibits such malpractices and prohibits anyone using the body or body parts for any purposes other than what was agreed. It seems that the practitioners attempt to generally cover all research or educational purposes by providing general terms in the consent forms in a futile attempt to safe guard themselves from an imminent ethical or legal litigation. It is always desirable that we specifically inform the donor what we intend to do with his body or body parts and their nature and extent. There have been concerns raised against using donated bodies in medical exhibitions at faculties of medicine or dentistry as according to the prevailing regulations it is not specified as a function of such body or parts display which require further analysis and discussion.

In regard to collecting specimens and body parts for forensic purposes, it is done as part of the post mortem examination in view of ascertaining a cause of death or identifying medical evidence supporting circumstance of death. Despite this being conducted through a court order or a inquirer's order, it is always desirable to obtain the informed consent of the next of kin. Further, in storing samples or using these specimens for purposes other than for what it was taken for, the practitioner has to 
obtain written consent giving reasons as to why they are taken and what they will be used for. For example, if the samples are taken in view of establishing a cause of death and the samples and the histology slides are used later for educational purposes, then informed consent for such has to be obtained from the relatives if the victim already did not have a directive in this regard. Further, as this was a legal referral the approval of the inquirer to sudden death or magistrate is needed (in addition to, from the relatives] if the specimens are used for any purpose other than what they were originally collected for. Not adhering to these good practices will not only be unethical but also be both ultra verus and form an offense punishable under the law. 